might be expected, as Nos. 2 and 3 are obviously descended from the hermaphrodite No. I. I have never, however, found a single individual in any' sense intermediate between No. 2 ancl 3 , which appear $(t)$ be two distinct female forms developed from No. I along different lines.

These two form:, it will be observed, differ remarkabiy from each other in the following points, viz. size of capitulum, size of florets and arrangement on the receptacle, colour of corolla, stoutness, colour and general form of style, and in the sbsence or presence of stellate hairs.

The stellate hairs are utilized to catch stray poller-grains detached from the bodies of insect-visitors coming from neighbouring hermaphrodites, most of which would otherwise be wasted. $A s$ it $i$, they are retained by the hairs uritil the arrival of other inects, which in depressing the already bent and twisted styles bring their viscid stigmas into contact with the pollen-crains collected by the hairs of adjacent florets- $\therefore$ result facilitated by the manner in which the stigma is set on the style. By this arrangement the chances of fertilization are much increased, as each stigma gencrally receives a full sliare of pollen.

With regari to the relative size of the three forms it is remarkable that while one of the female forms is st: much smaller than the iermaphrodite (as is the case, accorting to Darwin, in all gynodicecious species known to him), the other even exceeds it in size. It is also noteworthy that the capitulum of the second female form, although larger than that of the hermaphrodite, contains a much sualler number of forcts, and these are very larse.

I can discuver no rule as to the distribution of the d.fferent forms. In one station near here (a large common) all the plants are hemaphrodits. In a certain wood where the ipecies atounds, the "bent-styled" females appear to be ne urly as common as the leermaphrodites, while no "straight-styled" females can be found. In another wood, not half a mile distant from the first, the "bent-styled" form is almost entirely supplanted by the "straight-styled," which is plentiful. I, attly, in a fourth station (a barren strip of ground by the roadsi le), all three forms are found rrowing together. ARTHLik TUR $\mathrm{YTR}$

Box Ilill, September.

On the Aquatic Habits of Certain Land Tortoises.

Ir has always proved of more or less interest to me to observe the method of aquatic locomotion adopted in the part of any of our strictly terrestrial vertebrates, and never is this more keen than when the opportunity has been afforded to study the swimming propensities of certain of our lieptilia. Most snalies swim well, but who of us has not be:n surprised upon first observing the violent wriggling, frowardpropelling motions of some of the smaller lizards when they are thrown out into the water some little distance from the shore? The $A$ merican chamcleon (.tnolis frincipalis) well illustraics this last ; and this lizard, in common with others, seems to possess an actual dread of getting into deep water. For a lon's time it has been known that most species of the so-convidered stricter types of land tortoises soon drown when placed in water of any considerable depth, and it would be but natiral to suppose that sucl species would avoid that element as far as possible, but I have found this by no means always to be the case. Take the ordinary land turtle of the United States (Cistulo carolina for example: it will voluntarily enter the water under certain circumstances. $N o$ long ago the writer noticed one of these hunting for food in three or four inches of water along the edire of a pond that had rising banki; and the first time I discovered the nest of this variety the eggs were deposited in the water in a depression at the miry margin of a marsh. But this is not all, for if we place one o! these reptites upon a little island of land, well remored from the shore, and surrounded by water several feet in depth, and withdraw to watch its movement: we note that as soon as it satisfies itself as to its position, it will, without further ado, take at once to the water and swim to the nearest shore. It cloes not, lrowever, sink beneath the surface, but, holding it i head high out of that clement, and filling its lungs with air, strikes out vigorously, wit h alternate pairs of feet, until it accomplishes its purpose, and regains the mainland. How far one could swim in this manner I am unable to state, but that it would not exceed a few yards I am quite certain. N Nevcrtheless, even the power to accomplish the feat to the extent inticated might, under a variety of circumstances, have its influence upor. the distribution of the species, or of any species of typical lanci tortoise, and it would he interesting to know how far this power may tee enjoyed by this class of reptiles generaliy.

$$
\begin{aligned}
& \text { Smithsonian Institution, } \\
& \text { Washington, D.C., September } 13 .
\end{aligned}
$$

\section{Delambre's Analogies}

Four of the most important formula in spherical trigono. metry were given by Gauss, without proof, in his "Theoria Motus Corporum Coelestium" (1 809 ), and were therefore called Gauss's theorems or analogies.

They were, however, given by Ifollweide in Zach's Monatliche Correstondienz for November 1808 , anil before that by Delambre in the Connaissance dis. $7 \mathrm{cmps}$, issued in April 1807 , so that they are now justly ascribed to the latter.

They may be deduced in the most simple manner from Napier's analogies, and thus easily remembered.

Napier's anaiogies are-.

$$
\begin{aligned}
& \tan \frac{1}{2}(A \div B)=\begin{array}{l}
\cos \frac{1}{2}(a-b) \\
\cos \frac{1}{2}(a-b)
\end{array} \cdot \cot \frac{1}{2} \mathrm{C} \\
& \left.\tan \frac{1}{2} A-b\right)=\frac{\sin \frac{1}{2}(a-b)}{\sin \frac{1}{2}(a+b)} \cdot \cot \frac{1}{2} \mathrm{C} \\
& \tan \frac{1}{2}(a+b)=\begin{array}{lll}
\cos \frac{1}{3}(A & \cdots & B) \\
\cos \frac{1}{2}(A & -1 & B)
\end{array} \cdot \tan \frac{1}{2} c \\
& \tan \frac{1}{2}(a-b)=\frac{\sin \frac{1}{2}(A-B)}{\sin \frac{1}{2}(A+B)} \cdot \tan \frac{1}{b}(B
\end{aligned}
$$

Let $m \cdot \sin \frac{1}{2}(A+B)=\cos \frac{1}{2}(a-b) \cos \frac{1}{2} \mathrm{C}$.

$$
\therefore m \cdot \cos \frac{1}{2}(A+B)=\cos \frac{1}{2}(a+b) \sin \frac{1}{2} \mathrm{C} \text {. }
$$$$
\text { These are numerator and denominator of }(u) \text {. }
$$

Let $n \cdot \sin \frac{1}{2}(A-B)=\sin \frac{1}{2}(a-b) \cos \frac{1}{2} \mathrm{C}$. $\therefore \quad n \cdot \cos \frac{1}{2}(A-B)-\sin \frac{1}{2}(a+b) \sin \frac{1}{2} C$.

$$
\text { Numerator and denominator of }(\beta) \text {. }
$$

Siquare, and add-

$$
\therefore \quad m^{2}+n^{2}=\mathrm{I} \text {. }
$$

Inivide (4) by (2), and it follows by $(\gamma)$ that -

$$
\begin{gathered}
n=\tan \frac{1}{2} c ; \\
m m=\cos \frac{1}{2} c, n=\sin \frac{1}{2} c .
\end{gathered}
$$

Substitute these values, and (1), (2), (3), (4), are Delambre's analogies.

R. CHARTRES.

\section{Classified Cataloguing.}

TнЕ principle suggested by Mr. Petrie, on "Classified Cataloguing" (NATURF, August 22, 1. 392), is already successfully used in many of the chief libraries of the Lnited states, having been originated by Mr. Melville lewey, while I,ibrarian at Amherst College. It is equally applicable to collections of ail kinds, and the classification has already been extended to it considerable extent in certain departments, particularly in botany, and is capable of unlimited extension. It.posiesses al the advantages mentioned by Mr. Petrice, but is broader, inasmuch as it includes all subjects.

In the "I)ecimal Classification" of Mr. Dewey (Boston, I885, second edition), we find, for illustration, under 500 , General science; 58o, Botany ; 583 , Dicotyledona ; $53^{\circ} 9$, Apetalæ ; 583.95 , Uniscxuales, 583.951 , liuphorbiacex ; 590, Zoology ; 598, Reptiles; $598 \cdot 13$, Chelonia, dc.

If an extension of this system, which would, I have the means of knowing, he most acceptable to Mr. I) Wey, were to be adopted for general museum use, the advantages would be incalculable.

Polytechnic Socicty, Louisville, Kentucky.

\section{Valuable Specimens of Vertebrates for Biological Laboratories.}

WhAт specimens of Vertebrates are the best to be used by the student in the biological laboratory? This is certainly a very important question. In Europe, the following aniusals are gererally dissected: some fish, the common frog, the pigeon, 